\title{
The Relative Influences of Acidity and Polarity on Responsiveness of Small Organic Molecules to Analysis with Negative Ion Electrospray Ionization Mass Spectrometry (ESI-MS)
}

\author{
Trine Henriksen and René K. Juhler \\ Geological Survey of Denmark and Greenland (GEUS), Copenhagen, Denmark \\ Bo Svensmark \\ University of Copenhagen, Copenhagen, Denmark \\ Nadja B. Cech \\ University of North Carolina Greensboro, Greensboro, North Carolina, USA
}

\begin{abstract}
The purpose of the work presented here was to evaluate the influence of solution composition and analyte characteristics on responsiveness to analysis with negative ion electrospray ionization mass spectrometry. The responses of a series of structurally diverse acidic molecules were compared in various solvents. Response was generally observed to be higher in methanol than acetonitrile and response for all analytes was poorer when water was mixed with the organic solvent. A positive correlation between negative ion ESI-MS response and log P was observed when either acetonitrile or methanol was used as the electrospray solvent. This result was expected because analytes with significant nonpolar character should be particularly responsive to ESI-MS analysis due to their higher affinity for electrospray droplet surfaces. It was also predicted that highly acidic analytes would be most responsive to analysis with negative ion ESI-MS due to their tendency to form negative ions. However, for the analytes studied here, acidity was found not to have a consistent influence on ESI-MS response. Many of the highly acidic molecules were quite polar and, consequently, were poorly responsive. Furthermore, the deprotonated molecular ion was detected for a number of molecules with very high pKa values, which would not be expected to form negative ions in the bulk solution. Ultimately, these results indicate that acidity is not a conclusive parameter for prediction of the relative magnitudes of negative ion ESI-MS response among a diverse series of analytes. Analyte polarity does; however, appear to be useful for this purpose. (J Am Soc Mass Spectrom 2005, 16, 446-455) (c) 2004 American Society for Mass Spectrometry
\end{abstract}

I n recent years, high performance liquid chromatography coupled to electrospray ionization mass spectrometry has become a widely used technique for the analyses of environmental, pharmaceutical and biological analytes. Many of these analytes are small molecules that form singly-charged ions in the low mass range $(\mathrm{m} / \mathrm{z}<$ 400). Electrospray ionization mass spectrometry (ESI-MS) owes its popularity as a detector for these analytes to its specificity, sensitivity, and to the useful structural information that it yields. However, considerable variation in the electrospray ionization response is observed among

Published online February 5, 2005

Address reprint requests to Dr. N. Cech, University of North Carolina Greensboro, P.O. Box 26170, Greensboro, NC 27402, USA. E-mail: nadja_cech@uncg.edu small polar molecules and much time is often required to optimize the specific analytical conditions for a particular analyte. For this reason, a number of investigators have sought to understand the factors that influence the responsiveness of analytes to analysis with ESI-MS. Factors that have been studied include surface activity (affinity for electrospray droplet surfaces) [1-6], solvation energy of the analyte [3, 4, 7], and gas phase basicity [8]. Most of these factors have been studied in terms of their influence on positive ion ESI-MS; however, there are significant differences in the mechanisms and performance of positive ion versus negative ion ESI-MS $[9,10]$. Thus, further research into the factors governing analyte responsiveness to negative ion ESI-MS is warranted.

The research presented here compares the contributions of several factors to responsiveness of a series of 
analytes to analysis by negative ion ESI-MS. These analytes include a number of pesticides and pesticide metabolites, the analysis of which is of interest because they are common environmental contaminants. Numerous other analytes are included as well, and the conclusions drawn from this study apply not only to the pesticides but also to other acidic organic molecules. The information provided by this study advances the understanding of how negative ion ESI-MS response depends on analyte properties, and provides a basis for optimizing and predicting ESI response of specific analytes. This information is expected to facilitate troubleshooting and more effective method development for those who employ ESI-MS for the analysis of small molecules.

There are two main working hypotheses for the research described herein, the theoretical bases of which are discussed in detail in the Theory section. The first hypothesis is that response in negative ion ESI-MS should be positively correlated to $\log \mathrm{P}$, the logarithm of the octanolwater partition coefficient, which is used as a measure of analyte polarity. The second hypothesis is that response should be inversely proportional to analyte $\mathrm{pKa}$, a measure of analyte acidity. In cases where analytes have high pKa values and high $\log \mathrm{P}$ values, or vice versa, these hypotheses may be mutually exclusive. Therefore, the goal of the research presented here is to independently evaluate the validity of these two hypotheses and to determine which factor, acidity or polarity, is ultimately the more useful for the prediction of responsiveness to analysis with negative ion ESI-MS.

Only a few studies have previously been carried out that have attempted to correlate polarity and acidity with responsiveness in negative ion ESI-MS. Chiu and Lo studied negative ionization ESI response of substituted amides, considering primarily the acidity of these compounds [11]. Most amides are not acidic in aqueous solutions; thus, only a few pKa values were available for the amides evaluated. However, the general order of the ion intensities from the deprotonated amides was found to be in good agreement with expected acidity based on resonance effects in aromatic substitution. Schug and McNair compared the negative ionization response of six ibuprofen analogs of similar acidity (pKa values of 4.14 to 4.41) under various solvent conditions [12]. The preference to form cluster ions was found to be related to the structure and properties (such as polarity and nature of substituents) of the individual compounds. More recently, Schug and McNair examined the negative ionization response of a number of structurally similar analytes and related it to analyte structure, $\mathrm{pKa}$, and $\log \mathrm{P}$ [13]. ${ }^{\circ}$ These $^{\circ}$ studies $^{\circ}$ were carried out in a solution of 50:50 acetonitrile:water using a series of substituted benzoic acids with $\mathrm{pKa}$ values ranging from 2.85 to 4.94 . For these analytes, response of the deprotonated ion was found to be related to $\log \mathrm{P}$ but independent of $\mathrm{pKa}$.

The previous research indicates that acidity and polarity may both be important factors governing re- sponsiveness to negative ionization ESI-MS. However, it is difficult to extrapolate the results of previous studies to negative ion ESI-MS in general because they focused on only structurally similar analytes with a limited range of $\mathrm{pKa}$ values. The work presented here is a more comprehensive comparison of the influence of acidity and polarity on the responsiveness of thirty-one small acidic analytes to analysis with negative ion ESI-MS. Several different groups of structurally related analytes were included to facilitate comparison between structurally similar and structurally diverse compounds. These analytes have a wide range of $\mathrm{pKa}$ values (from 1.6 to 10.6), which allows for a more complete investigation of the relative importance of polarity versus acidity than has previously been published. Furthermore, the present work is novel because it includes an evaluation of the influence of solvent composition on the relationship between acidity, polarity, and ESI-MS response.

\section{Experimental}

\section{Chemicals}

Standards of most chemicals were purchased from SigmaAldrich (St. Louis, MO), ABCR (Karlsruhe, Germany) or Dr. Ehrenstorfer (Augsburg, Germany). O-desmethyl triazinamine was obtained from Maybridge Chemical Company (Cornwall, UK), and ammelide was donated by DuPont (Newark, DE). Purity of the standards used was the highest available, ranging from 98 to $99.8 \%$, except in the case of DNOC, which had a purity of $90 \%$. Methanol and acetonitrile were HPLC grade from Romil (Cambridge, UK), and water was purified using a Millipore system (Molsheim, France). Chloroform was purchased from BDH Laboratory supplies (Poole, UK). The chemicals used in this study are potentially hazardous to human health and should be handled only with appropriate protection (gloves and masks) under the fume hood.

\section{ESI-MS Analysis}

Analyses were performed with a Quattro Ultima triple quadrupole mass spectrometer from Micromass (Manchester, UK), equipped for electrospray ionization using nitrogen as nebulizer and desolvation gas $(600 \mathrm{~L} / \mathrm{h}$, $250{ }^{\circ} \mathrm{C}$ ). A negative potential of $2.8 \mathrm{kV}$ was applied to the stainless steel capillary ("capillary voltage") and the potential between the sampling cone and the skimmer ("cone voltage") was set to $60 \mathrm{~V}$. To minimize in-source fragmentation, a few compounds were analyzed at lower cone voltages; $20 \mathrm{~V}$ for the fluorobenzoic acids and $45 \mathrm{~V}$ for the phenoxyalkanoic acids. Temperature in the ion source was kept at $100{ }^{\circ} \mathrm{C}$.

Flow injection analyses were carried out using an HPLC system, Alliance 2695 from Waters (Milford, MA). The injected volume of $10 \mu \mathrm{L}$ of sample solution was transferred to the ESI-MS with a solvent flowrate at 
$0.150 \mu \mathrm{L} / \mathrm{min}$. ESI response was studied in neat methanol, neat acetonitrile, and aqueous mixtures (1:1) of each solvent. The MS analysis was performed in the full scan mode for the mass range $m / z 50$ to 450 .

Samples of each analyte were prepared both in methanol and in acetonitrile, and the sample solvent was chosen to match the flow injection solvent. Separate samples of each analyte were prepared at concentrations of $10^{-6}$ and $10^{-7} \mathrm{M}$ by serial dilution from concentrated stock solutions. Samples were analyzed at $10^{-7}$ and/or $10^{-6} \mathrm{M}$, depending on responsiveness of the analyte in the respective solvent.

\section{Data Analysis}

Values of $\log \mathrm{P}$ and $\mathrm{pKa}$ were calculated for each analyte using the molecular modeling program Chemsketch (Advanced Chemistry Development, Toronto, Ontario, Canada). For acidic analytes, the value of $\log \mathrm{P}$ is dependent on solution $\mathrm{pH}$, which is not always stated for experimentally determined $\log \mathrm{P}$ values. Conse- quently, the values used in this study were all calculated for the neutral compounds. The analyte ESI response was determined as the peak area of the relevant ion trace. In cases where there were significant isotopes or fragments, the analyte response was calculated as the

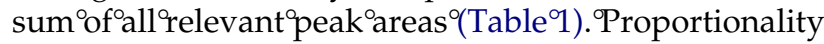
$( \pm 10 \%)$ was observed for the more responsive analytes, which gave measurable signals at both $10^{-7} \mathrm{M}$ and $10^{-6}$ M. Thus, proportionality was assumed for the analytes that were not detectable at $10^{-7} \mathrm{M}$, and their peak areas were extrapolated (by dividing the peak area at $10^{-6} \mathrm{M}$ by 10) to provide areas corresponding to a concentration of $10^{-7} \mathrm{M}$ such that comparison of responsiveness among the analytes was facilitated.

\section{Theory}

Ionization $^{\circ} \operatorname{can}^{\circ}$ occur $^{\circ}$ in $^{\circ}$ electrospray $^{\circ}$ ionization $^{\circ}$ mass spectrometry ${ }^{\circ}$ by $^{\circ} \mathrm{a}^{\circ}$ number ${ }^{\circ}$ of $^{\circ}$ different $^{\circ}$ mechanisms $\left[1-3,{ }^{\circ},{ }^{\circ} 14\right] .{ }^{\circ}$ Analyte ${ }^{\circ}$ ions ${ }^{\circ}$ may $^{\circ} \mathrm{be}^{\circ}$ formed by $^{\circ}$ the ${ }^{\circ}$ electrolytic oxidation or reduction that is inherent to the

Table 1. Relevant data and properties for the analytes of the study

\begin{tabular}{|c|c|c|c|c|c|c|}
\hline Analyte & CAS RN & $\mathrm{MW}(\mathrm{g} / \mathrm{mol})$ & $\mathrm{pKa}^{\mathrm{a}}$ & $\log P^{a}$ & $\mathrm{PA}^{\mathrm{b}}(\mathrm{kJ} / \mathrm{mol})$ & Ions $(m / z)$ \\
\hline \multicolumn{7}{|l|}{ Phenols } \\
\hline phenol & $108-95-2$ & 94.11 & 9.86 & 1.48 & 1466 & 93 \\
\hline 4-methylphenol & $106-44-5$ & 108.14 & 10.21 & 1.94 & 1471 & 107 \\
\hline 2,4-dimethylphenol & $105-67-9$ & 122.17 & 10.6 & 2.4 & & 121 \\
\hline 4-chlorophenol & $106-48-9$ & 128.56 & 9.47 & 2.43 & 1436 & $127+129$ \\
\hline 4-chloro-2-methylphenol & $1570-64-5$ & 142.59 & 9.87 & 2.89 & & $141+143$ \\
\hline 2,4-dichlorophenol & $120-83-2$ & 163.00 & 8.05 & 2.99 & & $161+163+165$ \\
\hline 2,4,5-trichlorophenol & $95-95-4$ & 197.45 & 7.1 & 3.71 & & $195+197+199$ \\
\hline pentachlorophenol & $87-86-5$ & 265.43 & 4.68 & 4.78 & & $263+265+267+269$ \\
\hline 4-fluorophenol & $371-41-5$ & 112.10 & 9.92 & 1.77 & 1455 & 111 \\
\hline 2,4-difluorophenol & $367-27-1$ & 130.09 & 8.72 & 2.04 & & 129 \\
\hline 4-nitrophenol & $100-02-7$ & 139.11 & 7.23 & 1.57 & 1372 & 138 \\
\hline DNOC & 534-52-1 & 198.13 & 4.42 & 2.2 & & 197 \\
\hline bromoxynil & $1689-84-5$ & 276.93 & 5.84 & 2.95 & & $274+276+278$ \\
\hline ioxynil & $1689-83-4$ & 370.92 & 6.01 & 3.6 & & 370 \\
\hline \multicolumn{7}{|l|}{ Benzoic acids } \\
\hline benzoic acid & $65-85-0$ & 122.12 & 4.2 & 1.89 & 1423 & 121 \\
\hline 4-fluorobenzoic acid & $456-22-4$ & 140.11 & 4.14 & 2.07 & 1410 & 139 \\
\hline 2,4-difluorobenzoic acid & $1583-58-0$ & 158.10 & 3.21 & 2.07 & & 157 \\
\hline 2,4,5-trifluorobenzoic acid & 446-17-3 & 176.09 & 2.87 & 2.32 & & 175 \\
\hline 2,3,4,5-tetrafluorobenzoic acid & $1201-31-6$ & 194.09 & 2.53 & 2.44 & & 193 \\
\hline pentafluorobenzoic acid & $602-94-8$ & 212.08 & 1.60 & 2.46 & 1354 & Not detected \\
\hline \multicolumn{7}{|l|}{ Phenoxy alkanoic acids } \\
\hline MCPA & $94-74-6$ & 200.62 & 3.14 & 2.49 & & $199+201+141+143$ \\
\hline $2,4-\mathrm{D}$ & $94-75-7$ & 221.04 & 2.98 & 2.58 & & $219+221+161+163$ \\
\hline mechlorprop (MCPP) & 93-65-2 & 214.65 & 3.19 & 2.83 & & $213+215+141+143$ \\
\hline dichlorprop (DCPP) & $120-36-5$ & 235.07 & 3.03 & 2.93 & & $233+235+161+163$ \\
\hline \multicolumn{7}{|l|}{ Triazines, miscellaneous } \\
\hline Diketo-metribuzin & $56507-35-0$ & 184 & 10.1 & -1.59 & & 183 \\
\hline Desaminodiketo-metribuzin & $52236-30-3$ & 169 & 7.81 & 0.92 & & 168 \\
\hline Cyanuric acid & $108-80-5$ & 129.08 & 4.93 & -1.41 & & 128 \\
\hline Ammelide & $645-93-2$ & 128.09 & 5.37 & -1.81 & & 127 \\
\hline o-desmethyltriazinamine & - & 126.12 & 6.0 & -1.67 & & 125 \\
\hline Uracil & $66-22-8$ & 112.09 & 9.2 & -0.71 & & 111 \\
\hline p-benzoquinone & $106-51-4$ & 108.10 & - & 0.27 & & 108 \\
\hline
\end{tabular}

aValues for pKa and log $\mathrm{P}$ were calculated with software from Advanced Chemistry Development, Toronto, Canada. Log $\mathrm{P}$ is calculated for the neutral species.

bProton Affinity of the negative ion (http://webbook.nist.gov/chemistry/). 
electrospray ${ }^{\circ}$ process $^{\circ}\left[15,{ }^{\circ} 16\right],{ }^{\circ}$ from ${ }^{\circ}$ acid $/$ base ${ }^{\circ}$ reactions within the electrospray droplets, or from gas phase proton transfer reactions that take place among ions that ${ }^{\circ}$ ave ${ }^{\circ}$ een ${ }^{\circ}$ liberated ${ }^{\circ}$ from $^{\circ}$ electrospray $^{\circ}$ droplets $^{\circ}[8]$. Most commonly, however, ESI-MS is employed for the analysis of analytes that exist as ions in the bulk solution prior to ESI analysis (so called "preformed" ions). In electrospray ionization of preformed ions, a small fraction of the ions in the solution are separated from their counter-ions by virtue of the positive or negative potential that is applied between the electrospray capillary and the counter electrode. These ions then reside on the surface of the droplets that are formed in the electrospray process, and eventually become free gas-phase ions either because of "ion evaporation $^{\prime \prime}[1]^{\circ}$ or $^{\circ}$ by $^{\circ}$ successive $^{\circ}$ fissioning ${ }^{\circ}$ steps $^{\circ}$ that ${ }^{\circ}$ ultimately lead ${ }^{\circ}$ to $^{\circ}$ droplets $^{\circ}$ that $^{\circ}$ only $^{\circ}$ contain $^{\circ}$ single ${ }^{\circ}$ ions ${ }^{\circ}[17]$.

For the ESI-MS analysis of preformed ions, analyte $\mathrm{pKa}$ is an important first parameter for the prediction of responsiveness to analysis with ESI-MS, particularly when choosing between the positive and negative ionization modes. A basic analyte is often analyzable in positive ion ESI-MS because it can be protonated to form a cation, while an acidic analyte can be deprotonated and analyzed in its anionic form using negative ion ESI-MS. For acidic analytes, the following wellknown equation describes the acid base reaction of the analyte with water:

$$
\mathrm{HA}+\mathrm{H}_{2} \mathrm{O} \leftrightarrow \mathrm{A}^{-}+\mathrm{H}_{3} \mathrm{O}^{+} \quad \mathrm{K}_{\mathrm{a}}=\frac{\left[\mathrm{H}_{3} \mathrm{O}^{+}\right]\left[\mathrm{A}^{-}\right]}{[\mathrm{HA}]}
$$

From eq 1 it is apparent that the acidic analytes (those with high Ka values and low $\mathrm{pKa}$ values), will tend to favor their deprotonated (anionic) forms in solution. Therefore, response in negative ion ESI-MS is expected to be inversely related to $\mathrm{pKa}$ for analytes that are ionized as a result of acid base reactions in the bulk solution or in the electrospray droplets.

An acid exists as approximately $90 \%$ in its deprotonated form when the $\mathrm{pH}$ of the bulk solution is one unit above the $\mathrm{pKa}$ value of the acid. Therefore, if acid/base reactivity were the only factor that influenced analyte responsiveness in ESI-MS, the response would be constant at increasing $\mathrm{pKa}$ values until $\mathrm{pKa} \approx(\mathrm{pH}-1)$, after which the response would be expected to decrease as less of the analyte existed in its ionized form. However, when organic solvents are used in the ESI analysis, the acid/base equilibrium reaction (eq 1) may be shifted to the left due to decreased solubility of the anionic form of the analyte. This would cause the response cut-off to shift to a lower $\mathrm{pKa}$ value than would be expected for an aqueous solution. On the other hand, it has been demonstrated that the $\mathrm{pH}$ of electrospray droplets can change significantly as those droplets evaporate and become ${ }^{\circ}$ more $^{\circ}$ concentrated $^{\circ}\left[18^{\circ}-20\right] .{ }^{\circ}$ This $^{\circ}$ would ${ }^{\circ}$ cause the pKa cut-off point predicted on the basis of acid/ base reactivity to shift to higher $\mathrm{pKa}$ values. Because of both of these factors, it may be difficult to predict the exact point at which response begins to depend on $\mathrm{pKa}$. Nonetheless, the general shape of the response versus $\mathrm{pKa}$ graph, and the order of responsiveness based on pKa values, should be valid even for analytes undergoing ESI-MS analysis in organic solvents.

Ionizability is not the only factor that contributes to selectivity in the ESI process. Significant differences in ESI-response are observed even among charged analytes $[4,14] .{ }^{\circ}$ An ${ }^{\circ}$ important ${ }^{\circ}$ factor ${ }^{\circ}$ that ${ }^{\circ}$ contributes ${ }^{\circ}$ to this selectivity is analyte polarity. A number of theories have been developed that help to explain the relationship between ${ }^{\circ}$ polarity ${ }^{\circ}$ and ${ }^{\circ}{ }^{2}{ }^{\circ}{ }^{\circ}$ response $\left[3,{ }^{\circ} 6,21-25\right] .{ }^{\circ}$ Of course, all analytes analyzable by ESI-MS will have a region of polarity where the charge resides on the molecule. However, the polarity of the rest of molecule can vary greatly. Generally, it is observed that charged analytes with significant nonpolar regions (termed "surface-active" ions) have higher ESI-responsiveness than their more polar counterparts. Evidence has been presented that the enhanced ESI-MS response that is observed for surface-active molecules is due to more effective competition for the excess charge that is produced $^{\circ}$ in $^{\circ}$ the $^{\circ}$ ESI-MS $^{\circ}$ process $^{\circ}\left[23,{ }^{\circ} 24\right] . .^{\circ}$ This $^{\circ}$ effect $^{\circ}$ has mostly been considered for molecules analyzed with positive ion ESI-MS.

Another important determining factor in ESI-MS responsiveness may be solvation energy. Tang and Kebarle $^{\circ}\left[3,{ }^{\circ} 4,{ }^{\circ} 26\right]^{\circ}$ suggested ${ }^{\circ}$ that ${ }^{\circ}$ analyte ${ }^{\circ}$ response ${ }^{\circ}$ was dependent the rate of evaporation of analytes from ESI droplets, which depended on the amount of energy required to transfer the solvated ion from solution to the gas phase (solvation energy). Solvation energy can be an effective parameter to predict responsiveness for analytes with equal surface activities (or those lacking significant ${ }^{\circ}$ surface $^{\circ}$ activity $)^{\circ}\left[3,{ }^{\circ} 7\right] .{ }^{\circ}$ However, ${ }^{\circ}$ surface activity in addition to evaporation rate must be considered ${ }^{\text {for }}$ most ${ }^{\circ}$ rganic analytes [3]. It ${ }^{\text {Is }}$ important to note that because surface-active analytes generally also have low solvation energy, these two effects may be hard to separate.

\section{Results and Discussion}

Results obtained from the analysis of a variety of small, acidic ${ }^{\circ}$ compounds $^{\circ}\left(\text { Table }^{\circ} 1\right)^{\circ}$ are $^{\circ}$ reported ${ }^{\circ}{ }^{\circ}$ the $e^{\circ}$ following sections. Structures of some of the more uncommon analytes are shown in Scheme 1. For clarity, the dependency of ESI response on analyte properties is primarily evaluated from the analyses in pure methanol, whereas the effects of varying solvents are treated separately. Standard deviations for triplicate analyses (in methanol) were below 5\%.

\section{Effect of Analyte Acidity}

Figure $^{\circ} 1 \mathrm{a}^{\circ}$ illustrates $^{\circ}$ the $^{\circ} \mathrm{ESI}^{\circ}$ response $^{\circ}$ of ${ }^{\circ}$ the ${ }^{\circ}$ phenols from Table 1 in ${ }^{\circ}$ neat ${ }^{\circ}$ methanol ${ }^{\circ}$ s $^{\circ}$ afunction $^{\circ}$ of their $\mathrm{pKa}$ values. A clear trend is observed of decreasing response at higher $\mathrm{pKa}$ values. This observation is in agreement 
Phenoxy alkanoic acids<smiles>Cc1cc(Cl)ccc1OCC(=O)O</smiles>

MCPA<smiles>O=C(O)COc1ccc(Cl)cc1Cl</smiles>

$2,4-D$

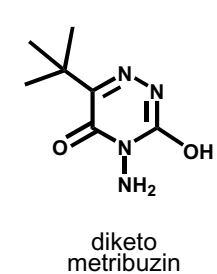<smiles>Cc1cc(Cl)ccc1OC(C)C(=O)O</smiles>

mechlorprop<smiles>CC(Oc1ccc(Cl)cc1Cl)C(=O)O</smiles>

dichlorprop
Phenols

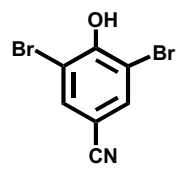

bromoxynil<smiles>Cc1cc([N+](=O)[O-])cc([N+](=O)[O-])c1O</smiles>

DNOC

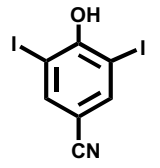

ioxynil
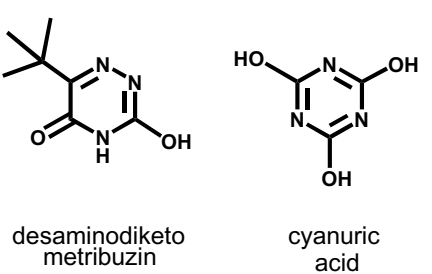

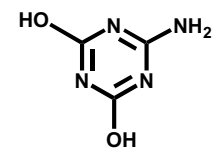

ammelide

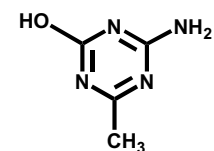

O-desmethyl triazinamine

Scheme 1. Structures of selected analytes.

with the inversely proportional relationship between $\mathrm{pKa}$ and negative ion ESI-MS response predicted in the Theory section. The leveling in response that occurs at very low $\mathrm{pKa}$ values is also in agreement with theoretical predictions. A constant, high response level is observed for the four most acidic phenols, which are expected to be completely in their deprotonated forms at neutral $\mathrm{pH}$.

The results of analyses including a broader range of

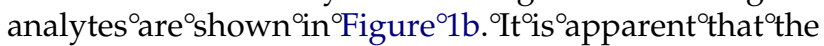
relationship between ESI-MS response and pKa becomes significantly more complicated when analytes of varying structures and functional groups are studied. Contrary to the trend for the phenols, the response of some compounds (primarily carboxylic acids) decreases at lower pKa values, and the triazine compounds do not follow any of these tendencies, all having very low response despite a broad range of $\mathrm{pKa}$ values. The poor response of the most highly acidic compounds is contrary to the prediction that highly acidic compounds should be highly responsive to ESI-MS analysis. These results show that acidity alone cannot predict responsiveness of negative ions to analysis with ESI-MS. The poor response of the highly acidic compounds can be attributed to their high degree of polarity, as discussed in the next section.

On the basis of solution phase chemistry, it might be expected that the least acidic analytes studied here would be completely undedectable by negative ion ESI-MS. However, this is not always the case. For example, 4-fluorophenol, which has a pKa value of 9.92, would not be expected to exist as a deprotonated ion in a solution of neat methanol. Nonetheless, it gives a negative ion ESI-MS signal one-hundred times greater than that of the background. This formation of negative ions in ESI-MS with solutions that have $\mathrm{pH}$ values below the analyte pKa has been observed previously [27], ${ }^{\circ}$ and ${ }^{\circ}$ may $^{\circ}{ }^{\circ}$ ccur $^{\circ}{ }^{\circ}$ or $^{\circ}$ several ${ }^{\circ}$ reasons. ${ }^{\circ}$ One ${ }^{\circ}$ is ${ }^{\circ}$ that ${ }^{\circ}$ the application of a very negative potential to the electrospray needle causes a condition in which the formation of negatively charged ions is energetically favorable, even for molecules that would not be deprotonated in the $^{\circ}$ bulk $^{\circ}$ solution $^{\circ}[14]^{\circ} .^{\circ}$ Another ${ }^{\circ}$ is ${ }^{\circ}$ that ${ }^{\circ}$ the ${ }^{\circ} \mathrm{pH}^{\circ}$ of electrospray droplets may be very different from that of the bulk solution. It has been documented for positive ionization ESI that the $\mathrm{pH}$ of the electrospray droplets is lower than that of the bulk solution, due to electrochemical reactions and evaporation of the neutral solvent that ${ }^{\circ}$ occur $^{\circ}$ during ${ }^{\circ}$ the ${ }^{\circ}$ electrospray ${ }^{\circ}$ process $^{\circ}\left[18^{\circ}-20\right]$. Conversely, it might be expected that the actual $\mathrm{pH}$ of electrospray droplets with negative ion ESI-MS is several units higher than 7 (perhaps closer to 10). This would explain why the ESI response of the analytes studied here, all of which have pKa values less than 10, is not entirely dependent on pKa. This would also explain why the results presented here are different than that of Chiu and Lo, who observed a dependency in ${ }^{\circ}$ ESI-response ${ }^{\circ}$ on $^{\circ}$ acidity $^{\circ}$ of $^{\circ}$ various $^{\circ}$ amides $^{\circ}[11] .^{\circ}$ The pKa values of the amides are much higher than those for the analytes used in this study. The predicted increase in solution $\mathrm{pH}$ for negative ionization ESI-MS has yet to be observed experimentally, and in fact, results of a study by Zhou et al. indicated a possible decrease in $\mathrm{pH}$ in evaporating droplets formed by negativeion ${ }^{\circ}$ ESI-MS [19]. ${ }^{\circ}$ However, ${ }^{\circ} \mathrm{Zhou}^{\circ} \mathrm{et}^{\circ}{ }^{\circ}{ }^{\circ}{ }^{\circ} \mathrm{did}^{\circ}$ suggest that the apparent decrease in $\mathrm{pH}$ observed in their experiments may have occurred only in the larger parent droplets, and that the offspring droplets formed 

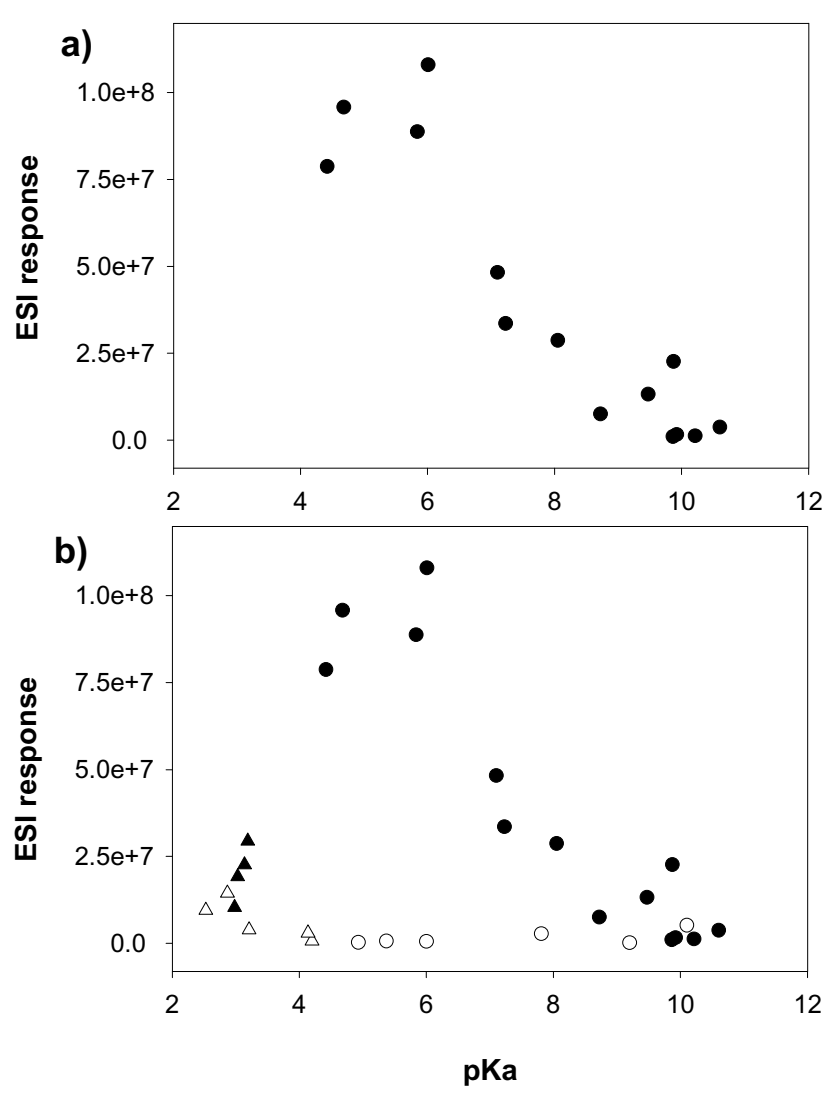

Figure 1. (a) ${ }^{\circ}$ ESI-response in ${ }^{\circ}$ methanol ${ }^{\circ}$ of ${ }^{\circ}$ the 9 phenols ${ }^{\circ}$ from ${ }^{\circ}$ Table 1 as function of analyte pKa. Analyses were performed using negative ion flow-injection ESI-MS. Each sample was run separately and its response was calculated as the area of the relevant selected ion trace. Responses were normalized to correspond to a concentration of $1 \times 10^{-7} \mathrm{M}$. As expected from theoretical predictions, response is inversely proportional to pKa. (b) Response ${ }^{\circ}$ of ${ }^{\circ}$ all ${ }^{\circ}$ the analyte ${ }^{\circ}$ from ${ }^{\circ}$ Table ${ }^{\circ}{ }^{\circ}$ as ${ }^{\circ}$ function ${ }^{\circ}$ of $^{\circ}$ analyte ${ }^{\circ} \mathrm{pKa}$. (filled circle) Phenols, (open triangle) benzoic acids, (filled triangle) phenoxyalkanoic acids, (open circle) triazines. Experimental conditions were the same as for part (a). The relationship between response and $\mathrm{pKa}$ is more complicated when this diverse series of analytes is studied.

in the ESI-MS process (the ones that eventually form ions) may, indeed, decrease in $\mathrm{pH}$ due to enrichment in $\mathrm{OH}^{-}$ions.

\section{Effect of Polarity}

As discussed in the Theory section, charged analytes with nonpolar portions tend to have a higher response in electrospray ionization mass spectrometry compared

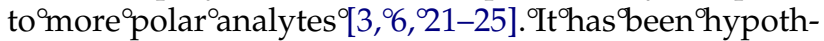
esized that the reason for this higher response is that charged molecules with nonpolar groups partition to the surface of electrospray droplets where the nonpolar groups are desolvated in air, minimizing the interactions that would occur with the polar electrospray solvent. The polar, charged portions of these molecules then reside at the very surface of the droplet, still in the polar solvent, where they carry the excess charge created $^{\circ}$ in $^{\circ}$ the ${ }^{\circ}$ electrospray $^{\circ}$ process $^{\circ}[23]^{\circ} .^{\circ}$ It $^{\circ}$ is ${ }^{\circ}$ because molecules with nonpolar groups exist as part of the excess charge phase that they would be expected to be more responsive to ESI-MS analysis than more polar molecules, which would tend to reside in the neutral interior of the electrospray droplets.

In this section, we use $\log \mathrm{P}$ as a measure of analyte polarity and correlate analyte responsiveness to this parameter. $\log \mathrm{P}$ is defined as the logarithm of the partitioning constant for a given molecule between octanol and water. Higher $\log \mathrm{P}$ values indicate a greater preference for the octanol (nonpolar solvent). Thus, analytes having high $\log \mathrm{P}$ values are expected to be more responsive to analysis with ESI-MS than analytes with low $\log \mathrm{P}$ values by virtue of their nonpolar character. The relationship between $\log \mathrm{P}$ and surface activity is not perfect, because an analyte must be completely solvated in order to partition into octanol, while it must only become partially desolvated (by air) in order to partition to the surface of an electrospray droplet. However, as mentioned in the Methods section, the $\log \mathrm{P}$ values used in these studies were calculated for the neutral compounds rather than their ionic forms. This may help to account for the discrepancy between surface activity and $\log$ P. Because it is likely to be the neutral portions of the molecule that determine its tendency to partition to the droplet surface, for predictions of responsiveness to electrospray ionization mass spectrometry, it may be most correct to consider partitioning only of the neutral compound. Ultimately, the demonstration of correlation between $\log \mathrm{P}$ and ESI-MS response would be useful because this parameter is readily calculated (using molecular modeling programs such as (hemsketch) and is, therefore, available to users of ESI-MS.

In agreement with expectations, the data illustrated in $^{\circ}$ Figure $^{\circ} 2^{\circ}$ demonstrate ${ }^{\circ}$ increasing ${ }^{\circ}$ response ${ }^{\circ}$ for ${ }^{\circ}$ analytes having $\log \mathrm{P}$ values greater than 1.5. A low level of

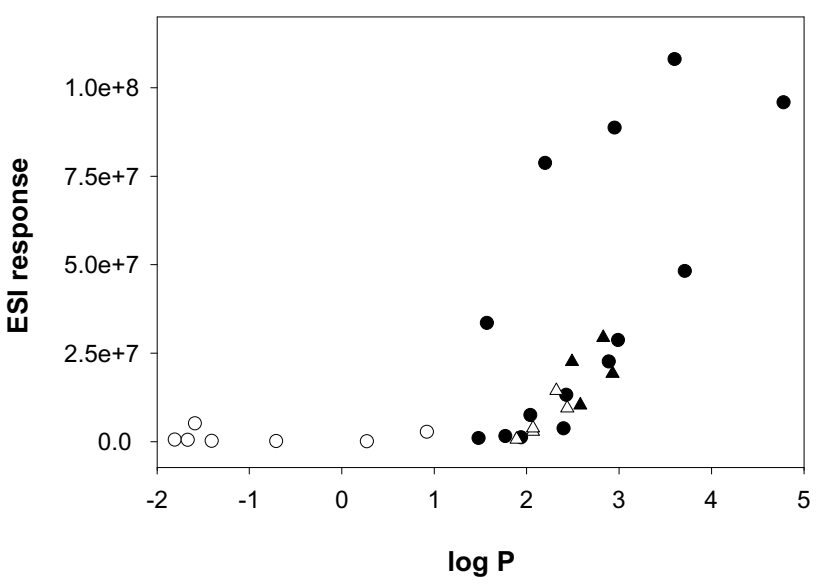

Figure 2. ESI response in methanol as function of analyte $\log \mathrm{P}$. (filled circle) Phenols, (open triangle) benzoic acids, (filled triangle) phenoxyalkanoic acids, (open circle) triazines. Response is positively correlated with $\log \mathrm{P}$ for analytes having $\log \mathrm{P}>1.5$. The four analytes that deviate by a higher response are $\mathrm{p}$ nitrophenol, DNOC, bromoxynil and ioxynil (left to right). 
response was observed for analytes below this critical value. This low level of response for the very polar analytes is in accordance with theoretical predictions. The analytes with $\log \mathrm{P}$ values below the critical value are likely to be better stabilized by the polar methanol than by the air-solvent interface at the droplet surface. Thus, these analytes do not become part of the excess charge phase on the surface of the electrospray droplets, and are neutralized by counter ions in the droplet interior. This effect of low response due to poor surface

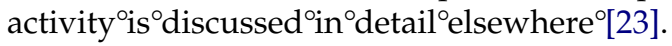

There are four analytes that deviate from the trend in Figure $^{\circ} 2:^{\circ}$ bromoxynil, $^{\circ}$ ioxynil, ${ }^{\circ} 4$-nitrophenol, ${ }^{\circ}$ and DNOC. These analytes that have a notably higher response than the other analytes of corresponding $\log \mathrm{P}$ values. The relationship between $\log \mathrm{P}$ and ESI-MS response of these four analytes is the same as for the other analytes (increases with approximately the same slope), but there appears to be some factor that increases the response of these analytes in a constant fashion. Future experiments could be carried out to evaluate the source of the anomalous high response observed for these analytes.

\section{Solvent Effects-Methanol Versus Acetonitrile}

The commonly used ESI solvents methanol and acetonitrile are quite similar with respect to surface tension, volatility, and dielectric constant. The most important difference is that methanol is a protic solvent, while acetonitrile is aprotic. Because of the protic nature of methanol, negative ions (and lone pairs) are more strongly solvated in methanol than acetonitrile, meaning that the protonated (neutral) form of the acid should be favored in acetonitrile and the deprotonated form in methanol. Thus, methanol was expected to be a more suitable solvent for negative ionization ESI-MS analysis of acidic compounds than acetonitrile. To evaluate the validity of this prediction, the response of all of the analytes ${ }^{\circ}$ from $^{\circ}$ Table $^{\circ} 1^{\circ}$ was $^{\circ}$ compared $^{\circ}$ in ${ }^{\circ}$ acetonitrile, methanol, and mixtures of these solvents with water. The results of this study for a representative set of analytes ${ }^{\circ}\left(\text { phenols }^{\circ}\right)^{\circ}$ are $^{\circ}$ displayed $^{\circ}$ in $^{\circ}$ Figure $^{\circ} 3 .^{\circ}$ Similar trends were observed for the other compounds studied. For all of the analytes except the most responsive ones, it is apparent that response in the protic solvent (methanol) is indeed much higher than that in the aprotic solvent (acetonitrile). This result is significant in that it demonstrates that response in negative ion ESI-MS for poorly responsive analytes can be improved by using methanol rather than acetonitrile as the spray solvent. Aside from the difference in magnitude of response, the same trends were observed for the use of acetonitrile as the spray solvent as those observed with methanol. The overall order of response among the analytes and the relationship between response and $\log \mathrm{P}$ and $\mathrm{pKa}$ were the same in both solvents.

\section{Response in Aqueous/Organic Solvent Mixtures}

When methanol and acetonitrile were mixed with water $(1: 1, \mathrm{v} / \mathrm{v})$, the difference in analyte response between the two $^{\circ}$ solvents $^{\circ}$ was $^{\circ}$ no $^{\circ}$ longer ${ }^{\circ}$ observed $^{\circ}\left(\text { Figure }^{\circ} 3\right)^{\circ} .^{\circ}$ This result lends further validity to the hypothesis that differences in response between acetonitrile and methanol are due to the protic/aprotic character of these solvents, because the addition of water to acetonitrile greatly increases the protic character of the solution. The results displayed $^{\circ}$ in $^{\circ}$ Figure $^{\circ} 3^{\circ}$ agree $^{\circ}$ with $^{\circ}$ those ${ }^{\circ}$ of $^{\circ} \mathrm{Jemal}^{\circ}$ and Hawthorn. In a comparison of negative ionization response of a sulphone compound in a number of aqueous mobile phases, these investigators observed no significant difference between solvents containing methanol and those ${ }^{\circ}$ containing ${ }^{\circ}$ acetonitrile $[28]$.

In accordance with what is commonly observed for ESI-MS analyses, the response of all of the analytes was poorer in solvents containing $50 \%$ water than it was in the ${ }^{\text {pure }}{ }^{\circ}$ organic ${ }^{\circ}$ solvents ${ }^{\circ}$ (Figure 3 ). ${ }^{\circ}$ Because ${ }^{\circ}$ of this, the magnitude of the differences in response among the different compounds was decreased as compared to the differences when methanol was used as the spray solvent, and it was somewhat more difficult to observe clear trends in response as a function of acidity or polarity. However, some trends were apparent, as shown in Figure 4 , which ${ }^{\circ}$ demonstrates ${ }^{\circ}$ the ${ }^{\circ}$ relationship between ${ }^{\circ}$ response $^{\circ}$ and $^{\circ} \mathrm{pKa}^{\circ}\left(\text { Figure }^{\circ} 4 \mathrm{a}\right)^{\circ}$ and ${ }^{\circ}$ response and ${ }^{\circ} \log ^{\circ} \mathrm{P}^{\circ}\left(\text { Figure }^{\circ} 4 \mathrm{~b}\right)^{\circ}$ when ${ }^{\circ} a^{\circ}$ methanol/water ${ }^{\circ}$ mixture is used as the spray solvent.

There was little correlation between response and analyte $\mathrm{pKa}$ in the methanol/water mixture, with the possible exception of the carboxylic acids (benzoic acids, open triangles, and phenoxyalkanoic acids, solid triangles), which demonstrated a weak negative relationship ${ }^{\circ}$ between ${ }^{\circ}$ response $^{\circ}$ and $^{\circ} \mathrm{pKa}^{\circ}$ (Figure $\left.{ }^{\circ} 4 \mathrm{a}\right){ }^{\circ}$ When response ${ }^{\circ}$ was $^{\circ}$ plotted ${ }^{\circ} a^{\circ} a^{\circ}$ function ${ }^{\circ}{ }^{\circ}{ }^{\circ} \log ^{\circ} \mathrm{P}^{\circ}$ (Figure $\left.{ }^{\circ} 4 b\right)$, a similar cut-off value in $\log \mathrm{P}$ was observed as was observed $^{\circ}$ with $^{\circ}$ the $^{\circ}$ methanol $^{\circ}$ spray $^{\circ}$ solvent $^{\circ}\left(\right.$ Figure $\left.^{\circ} 2\right)$. Also similar to the results with the methanol spray solvent, a positive correlation between response and log $\mathrm{P}$ was observed. There was, however, more scatter in the relationship between response and $\log \mathrm{P}$ for the methanol ${ }^{\circ}$ water $^{\circ}$ spray ${ }^{\circ}$ solvent $^{\circ}\left(\text { Figure }^{\circ} 4 \mathrm{~b}\right)^{\circ}$ compared $^{\circ}$ to the ${ }^{\circ}$ methanol ${ }^{\circ}$ spray $^{\circ}{ }^{\circ}$ solvent $^{\circ}\left(\right.$ Figure $\left.^{\circ} 2\right) .{ }^{\circ}{ }^{\circ}{ }^{\circ}{ }^{\circ}$ Close $^{\circ}$ inspection ${ }^{\circ}$ of ${ }^{\circ}$ Figure ${ }^{\circ} 4$, it $^{\circ}{ }^{\circ} s^{\circ}$ apparent ${ }^{\circ}$ that ${ }^{\circ}$ this ${ }^{\circ}$ is ${ }^{\circ}$ because ${ }^{\circ}$ there are two trends, one for the carboxylic acids (triangles) and one for the phenols (solid circles). For each compound class, analyte response increases with increasing $\log \mathrm{P}$, but the slope of the increase is greater for the carboxylic acids than that of the phenols.

The difference in response of the phenols compared to the carboxylic acids is likely due, in this case, to differences in acidity. The carboxylic acids, which are more acidic, would be expected to have higher response in ESI-MS than the phenols due to their increased tendency to form the $\mathrm{M}-\mathrm{H}^{-}$ion in solution. Note, however, that this difference in response for compounds of different acidity was not observed when neat 
a)

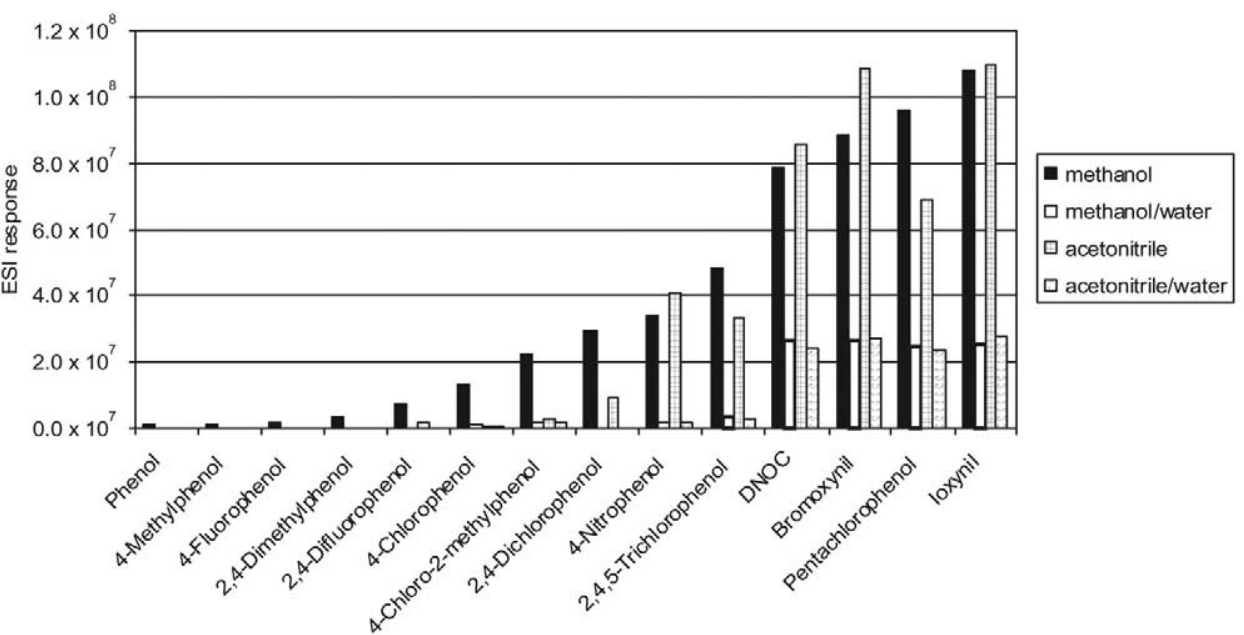

b)

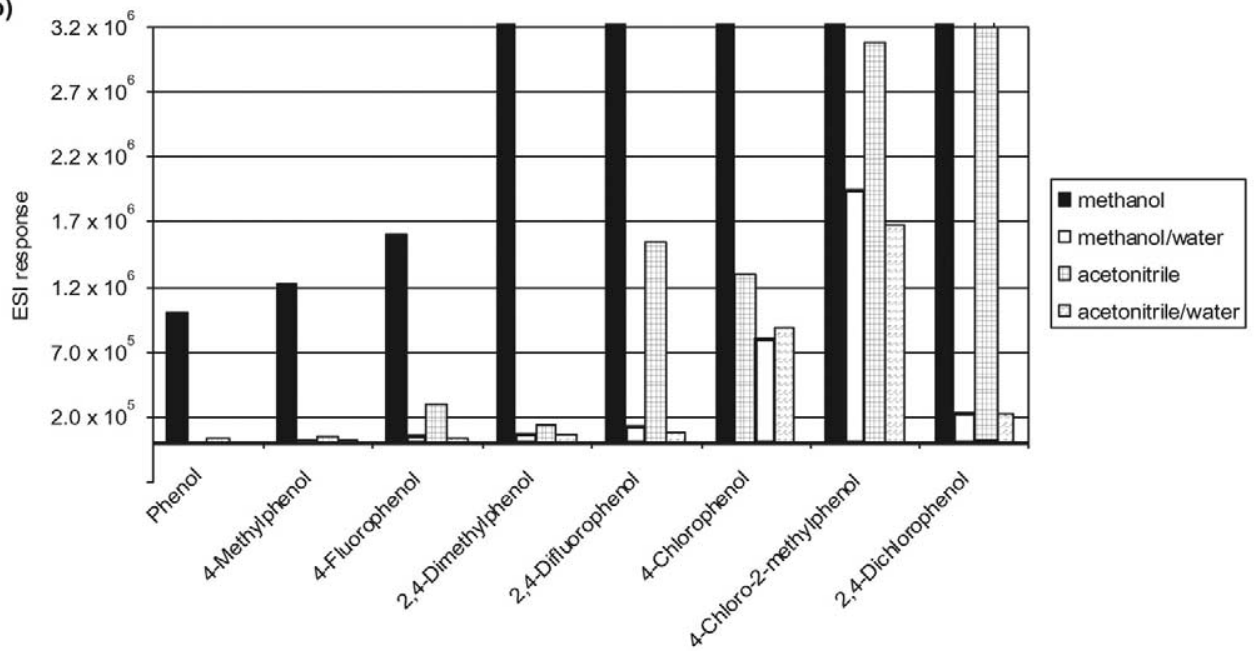

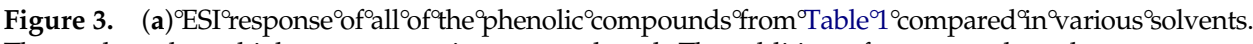
The analytes have highest response in neat methanol. The addition of water to the solvents causes a decrease in response of all analytes. Response in methanol:water (1:1) and acetonitrile:water (1:1) mixtures is similar. (b) An expanded view of the results for the less responsive analytes from Part a.

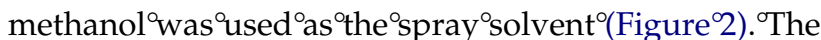
greater dependence on $\mathrm{pKa}$ observed for highly acidic analytes in the aqueous solvents indicates that the process of deprotonation is more of a limiting factor in the aqueous solvent than it is in organic solvents. This may be due to less efficient droplet charging at the capillary that occurs when aqueous solvents are used, as $^{\circ}$ described $^{\circ}$ by $^{\circ}$ Kostiainen $^{\circ}$ and $^{\circ}$ Bruins $^{\circ}[29],{ }^{\circ}$ or $^{\circ}$ due $^{\circ}$ to slower evaporation of the aqueous solvent that delays the increase in $\mathrm{pH}$ that may occur in negative ion ESI-MS. In addition, the analytes are likely to be more strongly solvated in aqueous solvents than they are in organic solvents, thus, the desolvation process may play a more significant role in this case than it did with the analyses in methanol.

Notably higher response was observed for some analytes: DNOC, bromoxynil, ioxynil, and pentachlorophenol. Three of these four analytes (DNOC, bromoxynil, and ioxynil) were also found to deviate when methanol $^{\circ}$ was $^{\circ}$ used $^{\circ}$ as $^{\circ}$ the $^{\circ} \operatorname{spray}^{\circ}$ solvent $^{\circ}\left(\right.$ Figure $\left.^{\circ} 2\right)$. However, ${ }^{\circ} \operatorname{comparison}^{\circ}$ of the ${ }^{\circ}$ results ${ }^{\circ}$ in ${ }^{\circ}$ Figures $2^{\circ}{ }^{\circ}$ and $4 \mathrm{~b}$ indicates that the response of the deviating analytes dose not depend on $\log \mathrm{P}$ in the same way in the methanol/water mixture as it does in neat methanol. In the methanol/water mixture, the excess response of the deviating analytes is of a constant level, while in the neat methanol the amount of excess response increased with increasing $\log \mathrm{P}$. The reason for the deviation among the four highly responsive analytes is unresolved and could be the topic of future research.

\section{Conclusions}

The results presented in this paper are significant to users of negative ion ESI-MS in several ways. First, it was observed that response in negative ion ESI-MS was positively correlated to $\log \mathrm{P}$ for a number of structurally diverse analytes in several different solvents. Thus, 

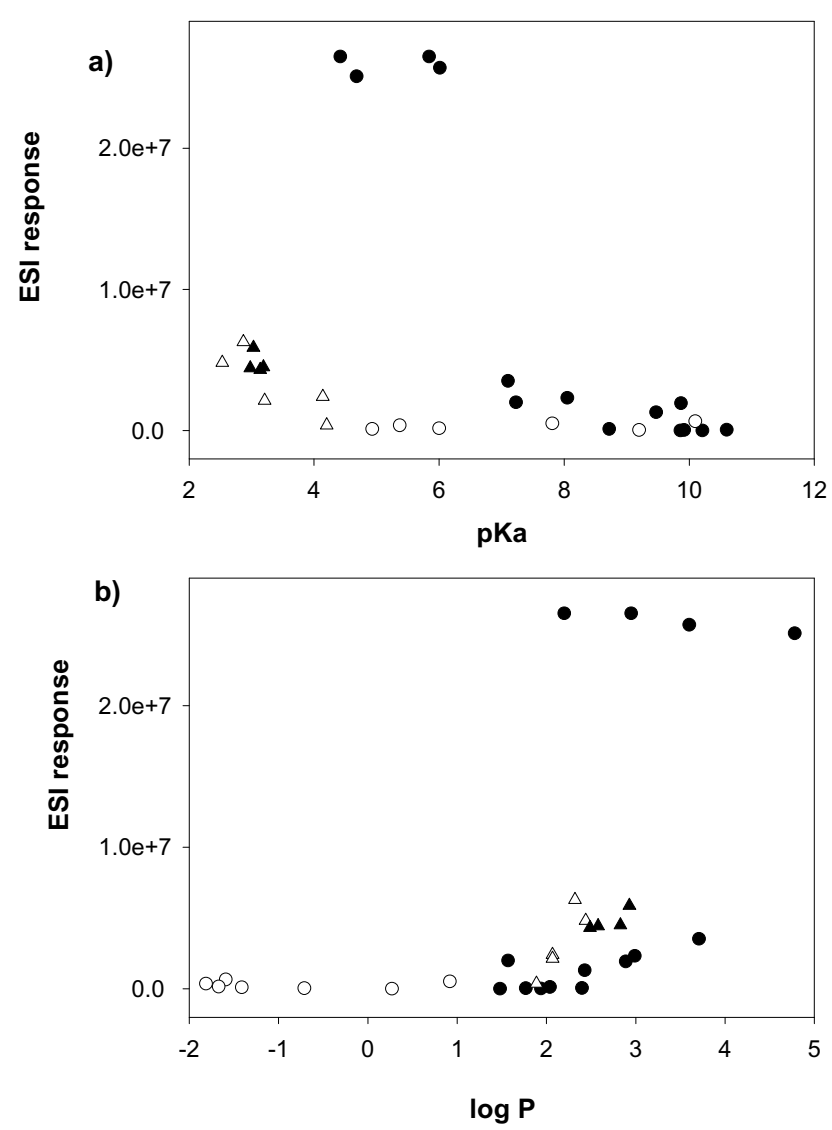

Figure 4. (a) ESI response in methanol:water (1:1) as function of pKa (filled circle) Phenols, (open triangle) benzoic acids, (filled triangle) phenoxyalkanoic acids, (open circle) triazines. There is little correlation between these two parameters, with the exception that response of the most acidic analytes (benzoic and phenoxyalkanoic acids) display a weak inversely correlation with pKa. (b) ESI response in methanol:water (1:1) as a function of $\log \mathrm{P}$. The difference in response among the analytes is less pronounced than in the neat methanol solutions. There are two separate correlations in this data, one for the benzoic acids and phenoxyalkonic acids, and one for the phenols. The cut-off point of $\log \mathrm{P} \cong 1.5$ is observed in the methanol/ water mixture as it was in neat methanol.

users of negative ion ESI-MS can expect higher response for negatively charged analytes with significant nonpolar portions, and can predict relative response based on calculated $\log \mathrm{P}$ values. Furthermore, it is apparent from these studies that methanol is the best solvent of those investigated for analysis of small negatively charged molecules with ESI-MS. When the conditions of the chromatographic separation permit, a better detection limit can be achieved for poorly responsive molecules with methanol than with acetonitrile. The addition of water to the solvent (either methanol or acetonitrile) causes a decrease in response in negative ion ESI-MS and results in poorer detection limits. Another consequence of the addition of water is that the difference in responsiveness in methanol versus acetonitrile disappears. Thus, when water must be included in the solvent to achieve successful HPLC separations, the choice of organic solvent (acetonitrile or methanol) can be made based on which is best to achieve optimal separation.

Given the results presented here, it is relevant to question whether analyte acidity is ever a useful parameter to consider when optimizing and trouble-shooting analytical methods for the analysis of small molecules with negative ion ESI-MS. It appears that it is, but only to a limited extent. The magnitude of an analyte's $\mathrm{pKa}$ value can be used to decide whether or not it will even form a negative ion, and therefore be analyzable with negative ion ESI-MS. Furthermore, the results of the analyses in methanol/water mixtures indicate that in aqueous mixtures, highly acidic analytes may be more responsive than less acidic analytes of similar polarity. However, as indicated by the studies presented in this paper, there are many cases where the relationship between electrospray response and acidity is not as simple as would be predicted on the basis of solution phase acid/base equilibrium. Many ions with very high pKa values are still able to form negative ions when subjected to negative ion ESI-MS analysis, and these ions may be quite responsive if they have significant nonpolar regions. Conversely, highly acidic analytes may respond very poorly to ESI-MS analysis if they are also very polar.

Due to the complexity of the ESI process, it is difficult to correlate responsiveness of small molecules to ESI-MS with any single parameter. This is demonstrated by the exceptions from the general tendencies observed for DNOC, bromoxynil, ioxynil, pentachlorophenol, and p-nitrophenol. Overall, however, analyte polarity, measured as the logarithm of the octanolwater partition coefficient $(\log \mathrm{P})$, appears to be a useful parameter for the prediction of ESI-MS responsiveness of small, acidic molecules. Analyte pKa is important as a first consideration when choosing between negative and positive ESI-MS. However, it does not generally prove useful for predicting relative response in a complex series of negatively charged analytes.

\section{Acknowledgments}

The authors thank Dr. Mark Bayliss of ACD Development (Toronto, Ontario) for the donation of the Chemsketch program used to calculate $\mathrm{pKa}$ and $\log \mathrm{P}$ values for this work. They also thank Professor Chris Enke at the University of New Mexico for helpful suggestions and review of the manuscript.

\section{References}

1. Iribarne, J. V.; Thomson, B. A. On the Evaporation of Charged Ions from Small Droplets. J. Chem. Phys. 1976, 64, 2287-2294.

2. Fenn, J. B. Ion Formation from Charged Droplets: Roles of Geometry, Energy and Time. J. Am. Soc. Mass Spectrom. 1993, 4, 524-535.

3. Tang, L.; Kebarle, P. Dependence of Ion Intensity in Electrospray Mass Spectrometry on the Concentration of Analytes in the Electrosprayed Solution. Anal. Chem. 1993, 65, 3654-3668.

4. Tang, L.; Kebarle, P. From Ions in Solution to Ions in the Gas Phase. Anal. Chem. 1993, 65, 972A-985A. 
5. Tang, K.; Smith, R. D. Physical/Chemical Separations in the Breakup of Highly Charged Droplets from Electrosprays. J. Am. Chem. Soc. 2001, 12, 343-347.

6. Zhou, S.; Cook, K. D. A Mechanistic Study of Electrospray Mass Spectrometry: Charge Gradients within Electrospray Droplets and Their Influence on Ion Response. J. Am. Soc. Mass Spectrom. 2001, 12, 206-214.

7. Wang, G. Cole, R. B. Charged Residue Versus Ion Evaporation for Formation of Alkali Metal Halide Cluster Ions in ESI. Anal. Chim. Acta. 2000, 406, 53-65

8. Amad, M. H.; Cech, N. B.; Jackson, G. S.; Enke, C. G. Importance of Gas-Phase Proton Affinities in Determining the Electrospray Ionization Response for Analytes and Solvents. J. Mass Spectrom. 2000, 35, 784-789.

9. Cole, R. B.; Harrata, A. K. Solvent Effect on Analyte Charge State, Signal Intensity, and Stability in Negative Ion Electrospray Mass Spectrometry; Implications for the Mechanism of Negative Ion Formation. J. Am. Soc. Mass Spectrom. 1993, 4, 546-556.

10. Voyksner, R. D. Combining Liquid Chromatography with Electospray Mass Spectrometry. In Electrospray Ionization Mass Spectrometry; Cole, R. B., Ed.; Wiley: New York, 1997; pp 323-341.

11. Chiu, F. C. K.; Lo, C. M. Y. Observation of Amide Anions in Solution by Electrospray Ionization Mass Spectrometry. J. Am. Soc. Mass Spectrom. 2000, 11, 1061-1064.

12. Schug, K.; McNair, H. M. Adduct Formation in Electrospray Ionization. Part I: Common Acidic Pharmaceuticals. J. Sep. Science. 2002, 25, 760-766.

13. Schug, K.; McNair, H. M. Adduct Formation in Electrospray Ionization Mass Spectrometry II: Benzoic Acid Derivatives. J. Chromatogr. A 2003, 985, 531-539.

14. Cech, N. B.; Enke, C. G. Practical Implications of Some Recent Studies in Electrospray Ionization Fundamentals. Mass Spectrom. Rev. 2002, 20, 362-387.

15. Van Berkel, G. J.; Quirke, J. M.; Tigani, R. A.; Dilley, A. S. Derivatization for Electrospray Ionization Mass Spectrometry. III. Electrochemically Ionizable Derivatives. Anal. Chem. 1998, 70, 1544-1554.

16. Van Berkel, G. J. Electrolytic Corrosion of a Stainless-Steel Electrospray Emitter Monitored Using an ElectrosprayPhotodiode Array System. J. Anal. At. Spectrosc. 1998, 13, 603-607.
17. Dole, M.; Mack, L. L.; Hines, R. L.; Mobley, R. C.; Ferguson, L. D.; Alice, M. B. Molecular Beams of Macroions. J. Chem. Phys. 1968, 49 , 2240-2249.

18. Gatlin, C.; Turecek, F. Acidity Determination in Droplets Formed by Electrospraying Methanol-Water Solutions. Anal. Chem. 1994, 66, 712-718.

19. Zhou, S.; Prebyl, B. S.; Cook, K. D. Profiling pH Changes in the Electrospray Plume. Anal. Chem. 2002, 74, 4885-4888.

20. Van Berkel, G. J.; Zhou, F.; Aronson, J. T. Changes in Bulk Solution $\mathrm{pH}$ Caused by the Inherent Controlled-Current Electrolytic Process of an Electrospray Source. Int. J. Mass Spectrom. Ion Processes 1997, 162, 55-67.

21. Pan, P.; McLuckey, S. A. The Effect of Small Cations on Positive Electrospray Responses of Proteins at Low pH. Anal. Chem. 2003, 75, 5468-5474.

22. Enke, C. G. A Predictive Model for Matrix and Analyte Effects in Electrospray Ionization of Singly-Charged Ionic Analytes. Anal. Chem. 1997, 69, 4885-4893.

23. Cech, N. B.; Enke, C. G. Relating Electrospray Ionization Response to Nonpolar Character of Small Peptides. Anal. Chem. 2000, 72, 2717-2723.

24. Cech, N. B.; Enke, C. G. The Effect of Affinity for Charged Droplet Surfaces on the Fraction of Analyte Charged in the Electrospray Process. Anal. Chem. 2001, 73, 4632-4639.

25. Cech, N. B.; Krone, J. R.; Enke, C. G. Predicting Electrospray Response from Chromatographic Retention Time. Anal. Chem. 2001, 73, 208-213.

26. Tang, L.; Kebarle, P. Effect of the Conductivity of the Electrosprayed Solution on the Electrospray Current. Factors Determining Analyte Sensitivity in Electrospray Mass Spectrometry. Anal. Chem. 1991, 63, 2709-2715.

27. Kelly, M. A.; Vestling, M. M.; Fenselau, C. C.; Smith, P. B. Electrospray Analysis of Proteins: A Comparison of PositiveIon and Negative-Ion Mass Spectra at High and Low pH. Org. Mass Spectrom. 1992, 27, 1143-1147.

28. Jemal, M.; Hawthorn, D. J. Effect of High Performance Liquid Chromatography Mobile Phase (Methanol Versus Acetonitrile) on the Postive and Negative Ion Electrospray Response of a Compound that Contains Both an Unsaturated Lactone and a Methyl Sulfone Group. Rapid Commun. Mass Spectrom. 1999, 13, 961-966.

29. Kostiainen, R.; Bruins, A. P. Effect of Solvent Composition on Dynamic Range and Sensitivity of Pneumatically-Assisted Electrospray (Ion Spray) Mass Spectrometry. Rapid Commun. Mass Spectrom. 1996, 10, 1393-1399. 